\title{
Design of a 5-MA 100-ns linear-transformer-driver accelerator for wire array $Z$-pinch experiments
}

\author{
Zhou Lin, ${ }^{*}$ Li Zhenghong, Wang Zhen, Liang Chuan, Li Mingjia, Qi Jianmin, and Chu Yanyun \\ Institute of Nuclear Physics and Chemistry, China Academy of Engineering Physics, \\ P.O. Box 919-226, Mianyang 621999, China
}

(Received 19 October 2015; published 24 March 2016)

\begin{abstract}
The linear-transformer-driver (LTD) is a recently developed pulsed-power technology that shows great promise for a number of applications. These include a $Z$-pinch-driven fission-fusion-hybrid reactor that is being developed by the Chinese Academy of Engineering Physics. In support of the reactor development effort, we are planning to build an LTD-based accelerator that is optimized for driving wire-array Z-pinch loads. The accelerator comprises six modules in parallel, each of which has eight series 0.8-MA LTD cavities in a voltage-adder configuration. Vacuum transmission lines are used from the interior of the adder to the central vacuum chamber where the load is placed. Thus the traditional stack-flashover problem is eliminated. The machine is $3.2 \mathrm{~m}$ tall and $12 \mathrm{~m}$ in outer diameter including supports. A prototype cavity was built and tested for more than 6000 shots intermittently at a repetition rate of $0.1 \mathrm{~Hz}$. A novel trigger, in which only one input trigger pulse is needed by utilizing an internal trigger brick, was developed and successfully verified in these shots. A full circuit modeling was conducted for the accelerator. The simulation result shows that a current pulse rising to $5.2 \mathrm{MA}$ in $91 \mathrm{~ns}(10 \%-90 \%)$ can be delivered to the wire-array load, which is $1.5 \mathrm{~cm}$ in height, $1.2 \mathrm{~cm}$ in initial radius, and $1 \mathrm{mg}$ in mass. The maximum implosion velocity of the load is $32 \mathrm{~cm} / \mu \mathrm{s}$ when compressed to 0.1 of the initial radius. The maximum kinetic energy is $78 \mathrm{~kJ}$, which is $11.7 \%$ of the electric energy stored in the capacitors. This accelerator is supposed to enable a radiation energy efficiency of $20 \%-30 \%$, providing a high efficient facility for research on the fast $Z$ pinch and technologies for repetition-rate-operated accelerators.
\end{abstract}

DOI: 10.1103/PhysRevAccelBeams.19.030401

\section{INTRODUCTION}

The fast $Z$ pinch offers an efficient means to generate high-power soft $\mathrm{x}$-ray radiation that can be employed to energize a hohlraum for inertial confinement fusion [1-3]. Facilities based on traditional Marx generators and waterline technologies, such as Saturn [4] and Z [5] [both located at Sandia National Laboratories (SNL)] and primary test stand (PTS) [6] [in China Academy of Engineering Physics (CAEP)], can deliver current rising to up to tens of megaamperes in $\sim 100$ ns into a wire-array $Z$-pinch load, driving it to implode and stagnate on the axis by the pinch effect. The stagnation process enables a conversion efficiency of up to $15 \%$ from the stored electrical energy to radiation [7]. This high efficiency provides a strong motivation for the pursuit of relevant technologies, such as the lineartransformer-driver (LTD), which was initiated by the High Current Electron Institute (HCEI) in Russia [8-14]. Considerable work [15-33] has been conducted worldwide

\footnotetext{
zhoulin_2003@163.com

Published by the American Physical Society under the terms of the Creative Commons Attribution 3.0 License. Further distribution of this work must maintain attribution to the author(s) and the published article's title, journal citation, and DOI.
}

over the past 15 years in development of LTD components and systems.

The LTD utilizes a number of bricks consisting of small capacitors and gas switches, the parameters of which are chosen to generate fast pulses directly. The output pulses of these bricks are inductively added through ferromagnetic cores. All the bricks and the cores are enclosed inside the accelerating cavity. High currents can be achieved by feeding each cavity core with many capacitors connected in parallel in a circular array. High voltage is obtained by inductively adding the output voltage of many cavities in series [18]. In addition to compactness in configuration and dependability in electrical insulation, the LTD has a number of significant advantages compared to traditional technologies. First and foremost, as all the components work under relative lower voltage and current, LTD cavities can be operated repetitively. This makes the LTD a promising candidate for $Z$-pinch inertial fusion energy (IFE) driver where the required repetition rate is estimated to be $0.1 \mathrm{~Hz}$. Meanwhile, the energy coupling efficiency of a LTD-based accelerator is supposed to be much higher, because fast pulses are generated directly without pulse compression networks, which wastes up to $\sim 50 \%$ of the stored energy. Furthermore, LTD drivers do not require insulating dielectric stacks for high voltage hold-off, in principle. The coaxial voltage adders, as well as the 
magnetically insulated transmission lines (MITLs), can be directly connected to the reaction vacuum chamber. Hence, the traditional stack-flashover problem is eliminated.

Based on LTD technology, the conceptual design for refurbishment of the Saturn accelerator was carried out by Mazarakis [34], using two conical MITL triplates, each driven by six voltage-adder modules. The vacuum transmission lines from each module join at the input to the conical MITL triplates in a vacuum convolute. The combined current is then transported to the $Z$-pinch load. The configuration of a 70-MA, 7-MV, 100-ns pulse, $0.1 \mathrm{~Hz}$, Z-IFE power plant was considered [35], in which an inductive annular chamber was used to connect the coaxial MITLs of 70 LTD modules. An experimental investigation using five 1-MA LTD cavities assembled in series into a voltage adder was conducted $[12,19]$. Meanwhile, waterline-based LTD drivers were proposed for petawatt-class $Z$-pinch accelerators [20-22], utilizing monolithic triplate radial-transmission-line impedance transformers to converge the output of LTD modules toward the vacuum section. However, it was assumed to use a six-level 6-mdiameter 24-MV vacuum insulator stack [20], which is a great challenge compared to the present 3.2-m-diameter 3.1-MV stack currently used in the $Z$ accelerator. On the contrary, the vacuum-line-based designs do not need vacuum stacks, but severe current loss may occur as the so-called "magnetic nulls" exist at the convolute or at inlets of the annular chamber. Therefore, it is necessary to address further investigations on relevant issues, such as the design of different transition geometries from the coaxial MITLs to the LTD loads, and determination of current loss in the MITLs as well as in the voltage adder.

We are developing a vacuum-insulated LTD accelerator which has a nominal 5-MA peak current and 100-ns rise time (10\%-90\%) on a wire-array Z-pinch load. The driver consists of six modules, each of which has eight cavities connected in series. Internal vacuum transmission lines from the interior of the adder to the Z-pinch load are utilized in the design. This accelerator is supposed to enable a conversion efficiency of more than $20 \%$ from the stored electrical energy to radiation. It will be used for studies on the physics of a relatively long implosion $Z$ pinch, like those carried out in Saturn when operated as a long pulsedpower generator. It also offers additional capabilities for the investigation of technologies for repetitively operated drivers that could be applied in the developing $Z$-pinchdriven fission-fusion-hybrid reactor at CAEP.

A prototype 0.8-MA LTD cavity and support systems were built and tested jointly with Northwestern Institute of Nuclear Technology, China. More than 6000 shots have been fired intermittently at a repetition rate of $0.1 \mathrm{~Hz}$. The cavity, described in Sec. II, consists of 36 bricks, one of which was configured as an internal trigger brick to generate trigger pulses for the others. Hence, only one input trigger pulse is needed. Furthermore, instead of using conventional charge and trigger resistors, the cavity uses charge and trigger inductors, which are significantly better for repetition-rated operation. Section III describes the configuration of the LTD accelerator, designed jointly with HCEI. Section IV presents an equivalent circuit modeling for the accelerator. Calculations on the basis of a OD thin shell model for the Z-pinch load are presented in Sec. V. In Sec. VI, conclusions are made and future studies are proposed.

\section{TESTS OF THE 0.8-MA CAVITY}

Figure 1 shows a picture of the 0.8-MA LTD cavity. It has 34 basic bricks which are composed of two 40-nF capacitors charged in opposite polarities and connected in series through a multigap gas switch. The switch has four gaps, each of which is $7 \mathrm{~mm}$, and is insulated by dry air of $0.26 \mathrm{MPa}$ while charged to $\pm 80 \mathrm{kV}$. These bricks are placed surrounding four metallic-glass-made cores with a volt-second integral of $18.3 \mathrm{mV} \mathrm{s}$ in total. Besides, the cavity has an internal trigger brick and a vacant brick for core premagnetization. The external diameter of the cavity is $2584 \mathrm{~mm}$, and the anode radius of the output line is $685 \mathrm{~mm}$.

A novel trigger was applied in the cavity utilizing an internal trigger brick, which consists of two 12-nF capacitors, a basic gas switch, and a $5.4 \Omega$ liquid resistor. This brick is connected to a special continuous trigger bus, depicted in Fig. 2(a). When the brick is fired, a high voltage pulse is generated and transmitted to points $A$ and $B$ at the same time and then to $C, D, E$, and $F$. Thus, the switches around the four arcs of the trigger ring are triggered simultaneously [36]. The cavity therefore needs only one external trigger pulse, which is currently $140 \mathrm{kV}$ in peak voltage and $\sim 20 \mathrm{~ns}$ in rise time. For comparison, the external trigger pulse was generated by two $\pm 40 \mathrm{kV}$ 40- $\mathrm{nF}$ capacitors connected in series and fed in via a $10-\mathrm{m} 50 \Omega$ high-voltage cable. Since the internal trigger brick is charged to a higher voltage, it is supposed to be qualified for triggering of the basic switches.

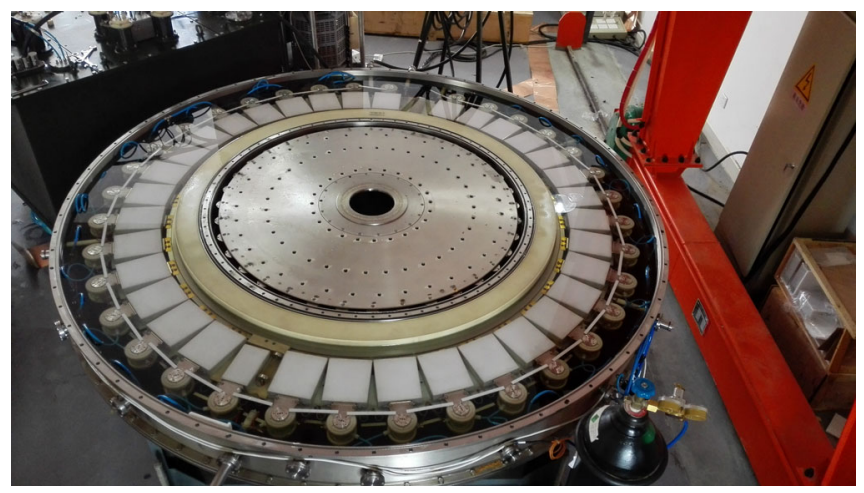

FIG. 1. View of the 0.8-MA prototype cavity with the top flange removed. 

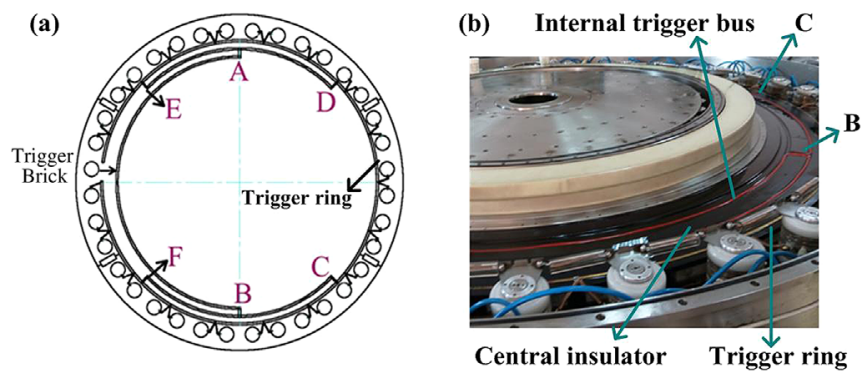

FIG. 2. (a) Principle of a novel trigger using an internal trigger brick. The pulse generated by the trigger brick is delivered to points $C, D, E$, and $F$ via $A$ and $B$; thus, switches around the four arcs are triggered simultaneously [36]. (b) A photograph of the trigger bus inside the central insulator, the top half of which is removed [36].

The trigger bus is made of $50-\mathrm{kV}$ rubber-covered wires and embedded in the central insulator, which consists of two fluted halves. Figure 2(b) shows a detailed photograph of the bus as well as the trigger ring, fixed in the insulator with the top half removed. To avoid insulation failures, the central insulator was set to be $14 \mathrm{~mm}$ thick.

Instead of using conventional charge and trigger resistors, the cavity uses charge and trigger inductors made of resistive springs, shown in Fig. 3. The charging spring has an inductance of $7 \mu \mathrm{H}$ and a resistance of $5 \Omega$. The trigger spring, which is $1.2 \mu \mathrm{H} / 0.16 \Omega$, is much smaller, because the trigger ring and internal trigger bus is a large inductor. Besides, there is a $5.4 \Omega$ liquid resistor in the internal trigger brick. These springs work lastingly at $0.1 \mathrm{~Hz}$ without any failures. They are significantly better than liquid and solid resistors, which would develop air bubbles or be shattered occasionally.

In order to evaluate repetition reliability, several automated support systems were developed, including capacitor charging, gas replacing, triggering, premagnetization, load connecting and opening, and data acquisition. All these systems are automatically operated at a repetition rate of $0.1 \mathrm{~Hz}$. In each shot sequence, the cavity is charged in $\sim 5 \mathrm{~s}$

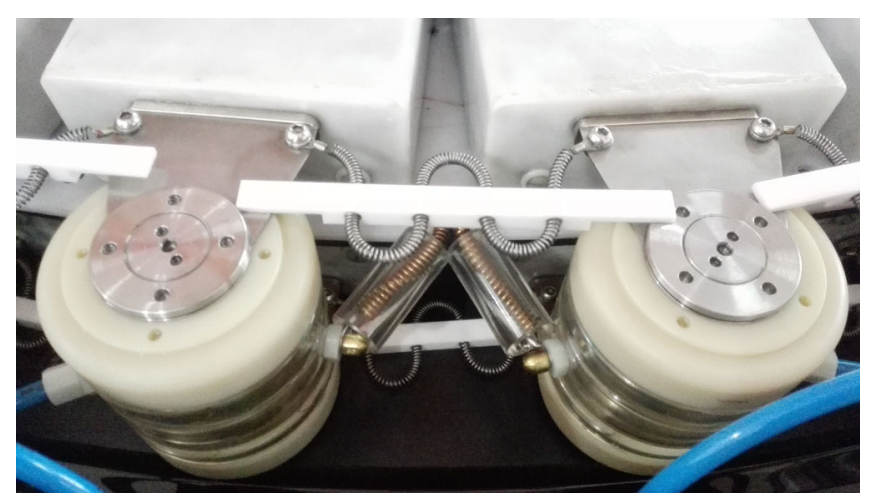

FIG. 3. Details of the connections with 40-nF capacitors, switches, and isolating inductors [36].

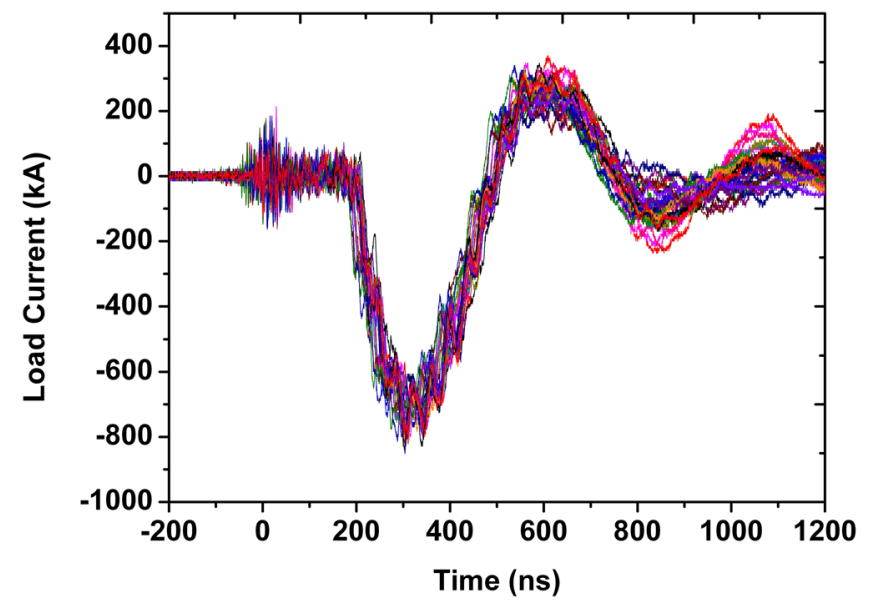

FIG. 4. Overlay of 30 consecutive shots when charged to $\pm 80 \mathrm{kV}$. The oscillograph was triggered by the input $140 \mathrm{kV} / 20$ ns pulse.

by a $120-\mathrm{kV}, 50-\mathrm{kW}$ power supply and then triggered by a $140-\mathrm{kV} / 20 \mathrm{~ns}$ pulse. The trigger pulse is formed and delivered to the cavity via a $50-\Omega, 150-\mathrm{kV}$ coaxial cable. All the switches and pipes are purged in $\sim 5 \mathrm{~s}$ after discharging. The exhaust gas is pumped into a 200-liter plenum which is held at a fraction of an atmosphere by two vacuum pumps capable of $\sim 36$ liters per second. New gas is supplied by a 20-liter air storage plenum which is pressurized to $0.5 \mathrm{Mpa}$. In order to accelerate the gas replacing, all the switches are directly connected to a torrid gas conduit with a sectional diameter of $20 \mathrm{~mm}$. Meanwhile, the magnetic cores are reset via a $4.6 \mathrm{kA}$ pulse input from the vacant brick in the cavity. The load of the cavity, consisting of 36 liquid resistors in parallel, is opened from the circuit automatically during premagnetization.

More than 6000 shots have been fired intermittently at a repetition rate of $0.1 \mathrm{~Hz}$. The output current pulses are well reproducible, as witnessed from Fig. 4, which overlays current pulses of 30 shots while capacitors are charged to $\pm 80 \mathrm{kV}$. The peak current on the $0.08 \Omega / 3.2 \mathrm{nH}$ liquid load is $\sim 0.7 \mathrm{MA}$, while the rise time is $\sim 90 \mathrm{~ns}(10 \%-90 \%)$. No failures with the capacitors, springs, or the trigger brick were observed. However, the switches prefire at a rate of one in each 30-50 shots. The rate increases sharply when charged to a higher voltage. Further optimizations on the switches should be addressed. To build a practical accelerator for $Z$-pinch experiments, the prefire probability of a single switch should be less than $10^{-5}$ when charged to $\pm 100 \mathrm{kV}$.

\section{CONFIGURATION OF THE LTD ACCELERATOR}

The architecture of the LTD-based accelerator is depicted in Fig. 5. The accelerator is composed of six modules, each consisting of eight stacked annular cavities in an inductivevoltage-adding (IVA) configuration. Thus, 48 cavities are needed, utilizing 3360 capacitors and 1680 gas switches. 


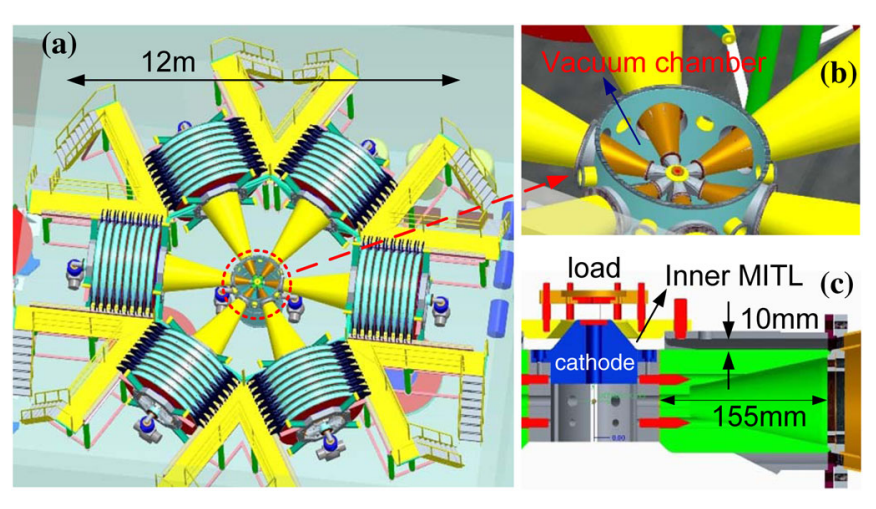

FIG. 5. (a) The architecture of the LTD accelerator for Z-pinch experiments [37]. (b) The vacuum chamber in which the wirearray load is located. (c) The transition from the conical outer MITL to the radial inner one.

Based on the trigger presented in Sec. II, only 48 trigger pulses are needed. The current of each IVA is delivered, via the outer MITL, into the vacuum chamber, which is shown in Fig. 5(b). In this chamber, each of the six conical MITLs is connected to the radial inner MITL via a transition, depicted in Fig. 5(c). The combined current is then transported to the $Z$-pinch load.

The IVA in each module is $1.84 \mathrm{~m}$ long and $2.6 \mathrm{~m}$ in overall diameter. The anode of the secondary line, which is formed by the inner cylindrical wall of the cavities, is $1370 \mathrm{~mm}$ in diameter. The cathode is composed of stepped cylinders. The $A-K$ gap should be large enough to avoid severe current loss. Meanwhile, it cannot be too large to introduce a big inductance, which reduces the current. The gap is set to be $1 \mathrm{~cm}$ at the first stage and increases at a rate of $1 \mathrm{~cm}$ per stage.

The outer MITL of each module consists of two conical stages, the first of which is located outside the chamber while the second is inside. The first is $2077 \mathrm{~mm}$ in axial length and $7.45-3.85 \Omega$ in vacuum impedance. The diameter of the anode is $1370 \mathrm{~mm}$ at the inlet and
$330 \mathrm{~mm}$ at the outlet, while that of the cathode is 1210 and $310 \mathrm{~mm}$, respectively. The downstream stage is $508 \mathrm{~mm}$ long with an $A-K$ gap of $10 \mathrm{~mm}$ in constant. The vacuum impedance is $3.85-16.41 \Omega$. Each of the conical outer MITLs is connected to the radial inner MITL via the transition, which has an $A-K$ gap of $10 \mathrm{~mm}$.

There is no insulating stack in the LTD design as is necessary in a traditional accelerator. The only insulators used are the $\sim 1.5 \mathrm{~m}$-in-diameter plastic rings in each of the low-voltage $(\sim 100-\mathrm{kV})$ accelerating gaps of the modules. Therefore, the traditional stack-flashover problem is eliminated. Meanwhile, the transmitting time from the first stage of a module to the $Z$-pinch load is only $15 \mathrm{~ns}$, and the reflecting energy from the load can be reflected at the stages and coupled to the load again. Therefore, the accelerator could possess a high-energy efficiency. Besides, the LTD design is compact. The whole facility is $3.2 \mathrm{~m}$ tall and $12 \mathrm{~m}$ in outer diameter including supports.

\section{EQUIVALENT CIRCUIT MODELING FOR THE ACCELERATOR}

A schematic of the accelerator as well as the $Z$-pinch load is shown in Fig. 6. Each LTD stage is denoted by a $R L C$ circuit, being added to the module via a radial transmission line $T_{r}$. The secondary line of a stage is divided into seven elements, each of which is $0.11 \mathrm{~ns}$ in time delay. The outlet of the adder is connected to the outer MITL consisting of 81 elements. Each element has a timedependent shunt resistor $R_{\text {loss }}$, indicating current loss to the anode. The six uniform modules in parallel are linked together via the transitions, denoted as an inductance $L_{S Q}$ in each module. All the module outputs are transported to the $Z$-pinch load via the inner MITL, which is indicated by inductance $L_{z}$.

A transmission-line-circuit code [38] was built in the modeling. The voltage adder is characterized in the way shown in Fig. 7, where $E_{m}$ is the open-circuited voltage of the left transmitting wave at the inlet of an element and $E_{p}$

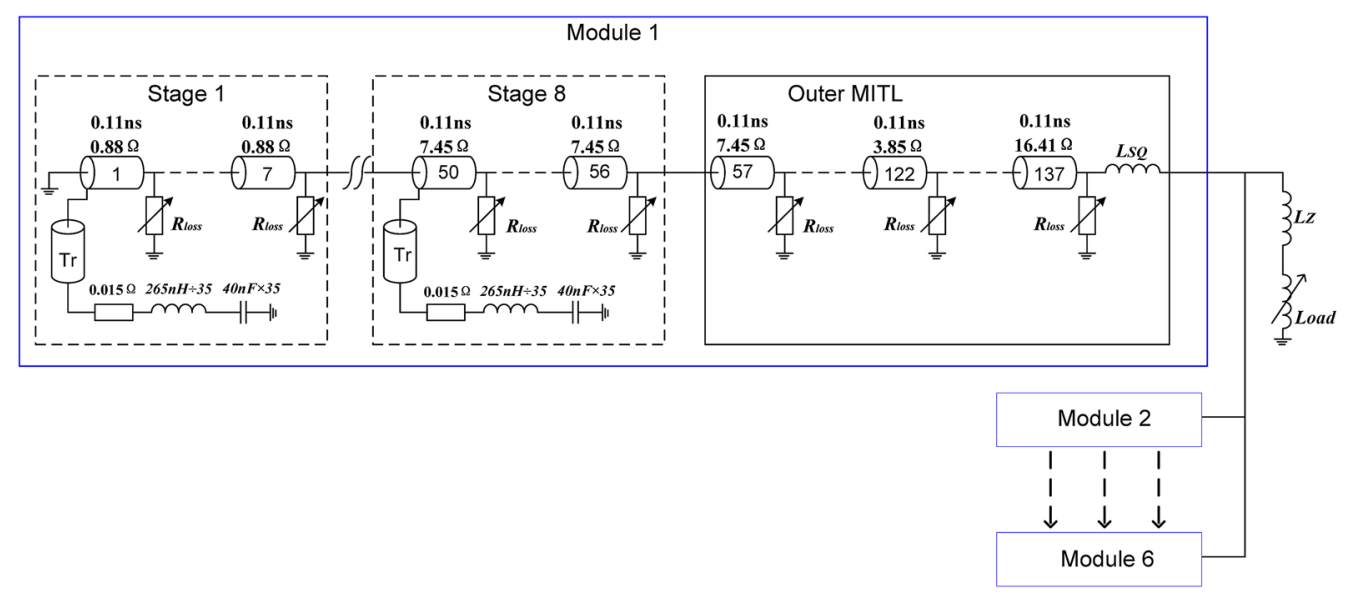

FIG. 6. Schematic model of the accelerator. 


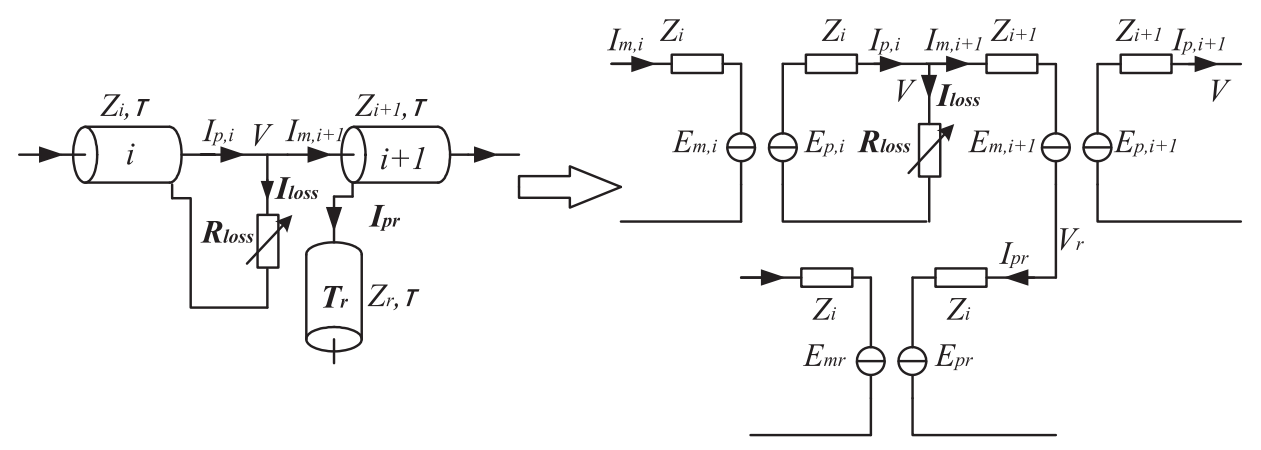

FIG. 7. Equivalent circuit of three elements in a voltage-adder configuration.

is that of the right transmitting wave at the outlet. $Z$ is the impedance and $\tau$ is the time delay. $I_{\text {loss }}$ represents the current loss of the upstream element such as that which occurs at the early stage of magnetically insulation. Note that

$$
E_{p, i+1}(t+\tau)=2\left[V(t)-V_{r}(t)\right]-E_{m, i+1}(t)
$$

For MITLs, the circuit modeling is complicated by the electron flow, which occurs when the electric field strength on the cathode exceeds the vacuum explosive emission threshold in an element. The electron flow reduces the impedance of transmission lines below their vacuum value $Z_{0}$. An accurate representation of MITL elements in a circuit code requires transmission line elements with variable effective impedance, such as the flow impedance $Z_{f}$, which is determined via Mendel's MITL theory $[39,40]$. However, since $Z_{f}, I_{p}$, and $V$ of an element affect each other, the numerical solution is difficult and unstable, especially in the uninsulated state in which current loss occurs on account of electrons crossing the $A-K$ gaps. Nevertheless, the problem can be simplified. The voltage of a $Z$-pinch accelerator, compared to the current, is relatively low. Soon after magnetic insulation is established, the current in a MITL element is significantly larger than the critical value. Thus, the MITL is deeply superinsulated, and only a few parts of the total current are carried by the MITL flow electrons. Consequently, the contribution of the vacuum electrons can be ignored without introducing fatal errors. So, we can make a reasonable approximation of simply treating $Z_{0}$ as a MITL impedance in the modeling. Therefore, the key issue of the modeling is to determine $I_{\text {loss }}$ for each MITL element at each time step.

A practical model for $I_{\text {loss }}$ is expressed as $[6,41]$

$$
I_{\text {loss }}=S J_{\mathrm{CL}}(V) F_{e}\left(I_{a} / I_{\text {critical }}\right) K\left(t, E_{\text {max }}\right),
$$

where $S$ is the surface area of the anode for an element and $J_{\mathrm{CL}}$ is the current density given by the Child-Langmuir law. $F_{e}$ is an artificial function which reflects the threshold dependence on the anode current $I_{a}$, expressed as

$$
F_{e}(Y)= \begin{cases}\sqrt{1-\left(I_{a} / I_{\text {critical }}\right)^{2}}, & I_{a}<I_{\text {critical }}, \\ 0, & I_{a} \geq I_{\text {critical }}\end{cases}
$$

where $I_{\text {critical }}$ is the critical value for magnetic insulation. $K\left(t, E_{\max }\right)$ is a function for the use of denoting the emission intensity as

$K\left(t, E_{\max }\right)= \begin{cases}0, & E_{\max }<E_{1}, \\ \sin ^{2}\left(\frac{\pi}{2} \frac{E_{\max }-E_{1}}{E_{2}-E_{1}}\right), & E_{1}<E_{\max }<E_{2}, \\ 1, & E_{\max }>E_{2},\end{cases}$

where $E_{\max }$ is the maximum electric field strength on the cathode until the active calculating time. $E_{1}$ and $E_{2}$ are the lower and upper limit, respectively, of the electrical field strength in which the emission ability increases from 0 to 1 .

A zero-dimensional (OD) model was employed in the calculation. The load is treated as a thin shell pushed by the magnetic pressure of the driving current. The shell has an initial radius of $R_{0}$, a current return can radius of $R_{\mathrm{RC}}$, a linear mass of $m$, and a length of $l$. The acceleration of the shell is given as

$$
a(t)=\frac{\mu_{0} I(t)^{2}}{4 \pi m r(t)},
$$

where $\mu_{0}$ is the permeability of the vacuum, $I(t)$ is the pinch current, and $r(t)$ is the radius of the load. The load acts as a time-dependent inductor, which is obtained from the following expression:

$$
L(t)=\frac{\mu_{0} l}{4 \pi} \ln \left(\frac{R_{\mathrm{RC}}}{r(t)}\right) .
$$

\section{SIMULATION RESULTS}

Since the intrinsic output time of the LTD accelerator is relatively long due to the large inductance in IVAs and MITLs, the mass and initial radius of the load should be chosen to permit a longer implosion time to couple more energy from the electromagnetic pulse to the pinch load. 


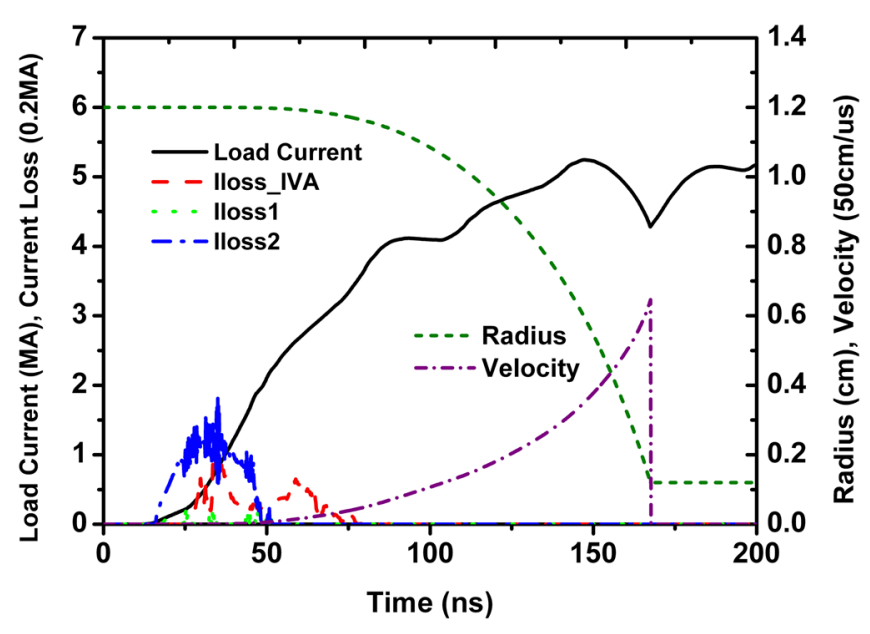

FIG. 8. The load current, loss current, load radius, and implosion velocity calculated with a OD implosion model coupled to a circuit model for an initial mass of $1 \mathrm{mg} / \mathrm{cm}$. Iloss_IVA is the current loss in a voltage adder. Iloss 1 and Iloss 2 represent current losses that occur in the upstream stage and downstream stage of the outer MITL, respectively.

Figure 8 shows the current, radius, and imploding velocity obtained from the simulation, in which the load was set as $R_{0}=1.2 \mathrm{~cm}, R_{\mathrm{RC}}=4 \mathrm{~cm}, m=1 \mathrm{mg} / \mathrm{cm}$, and $l=$ $1.5 \mathrm{~cm}$ and all the cavities are charged to $\pm 100 \mathrm{kV}$ and triggered simultaneously. A current pulse rising to 5.2 MA in $91 \mathrm{~ns}(10 \%-90 \%)$ was delivered to the load.

Iloss_IVA represents the total current loss that occurs in the voltage adder of a module, while $E_{1}$ and $E_{2}$ were set to be 200 and $300 \mathrm{kV} / \mathrm{cm}$, respectively. Iloss 1 and Iloss 2 are the current losses in the upstream stage and the downstream stage of the outer MITL, respectively. It can be seen that the current loss mainly occurs in the downstream stage of the outer MITL. The peak value is $\sim 0.3 \mathrm{MA}$ in each module, and the duration is $\sim 30 \mathrm{~ns}$. Moreover, there is current loss that occurs in the IVA, which arises $\sim 10$ ns later than Iloss1 and lasts for 40-50 ns. Additional simulation shows that Iloss_IVA can be eliminated by reducing the charging voltage of each cavity to $\pm 90 \mathrm{kV}$, because the electric field stress in the IVAs is then less than $E_{1}$.

Figure 9 shows the current and voltage at the outlet of unit 56. The cathode current $I_{c}$ is acquired from the following equation [39]:

$V=Z_{0} \sqrt{I_{a}^{2}-I_{c}^{2}}-\frac{m_{0} c^{2}}{2} \frac{I_{a}^{2}-I_{c}^{2}}{I_{c}^{2}}=Z_{f} \sqrt{I_{a}^{2}-I_{c}{ }^{2}}$.

This equation is valid only in a transmission line where the electron emission threshold has been exceeded and the magnetic insulation is established. Thus, $I_{c}$ arises when $I_{a}$ is larger than the critical current. Besides, in the first few nanoseconds of the pulse, no electron emission occurs, and thus $I_{c}$ equals $I_{a}$.

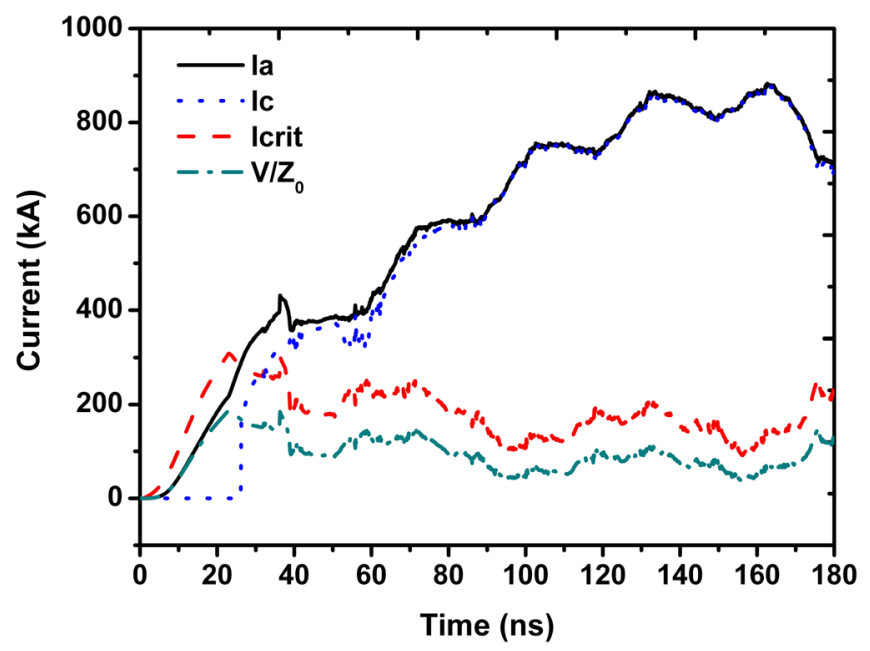

FIG. 9. Waveforms of the current and voltage at the outlet of unit 56. $I_{a}$ and $I_{c}$ are the total current and cathode current, respectively. $I_{\text {crit }}$ is the critical current for magnetically insulation. $V$ is the voltage, and $Z_{0}$ is the vacuum impedance. Note that $I_{c}$ is obtained via Eq. (7); thus, it arises only when $I_{a}$ is larger than $I_{\text {crit }}$.

The critical current $I_{\text {crit }}$ is calculated from Ref. [42]:

$I_{\text {crit }}(V)=\frac{V}{Z_{0} f_{\mathrm{SL}}(V)}\left(\frac{1}{2 f_{\mathrm{SL}}(V)-1}\right)^{1 / 2}$,

$f_{\mathrm{SL}}(V)=\left(\frac{\frac{V_{0}}{4 V}-1}{\frac{V_{0}}{V}-1}\right) \pm\left[\left(\frac{\frac{V_{0}}{4 V}-1}{\frac{V_{0}}{V}-1}\right)^{2}+\frac{1}{\frac{V_{0}}{V}-1}\right]^{1 / 2}$,

where $V_{0}=0.255 \mathrm{MV}$. It can been seen that $I_{a}$ is significantly larger than $I_{\text {crit }} 30-40$ ns after magnetic insulation is established. Consequently, $I_{c}$ approaches $I_{a}$, and the flow current can be ignored.

To estimate the maximum implosion velocities and kinetic energies, a 10:1 compression ratio was assumed. The shell moves acceleratedly during the whole implosion. When compressed to 0.1 of the initial radius, the velocity can be as high as $32 \mathrm{~cm} / \mu \mathrm{s}$, resulting in a kinetic energy of $78 \mathrm{~kJ}$, which is $11.7 \%$ of the electric energy stored in the capacitors. The imploding time is $136 \mathrm{~ns}$ from the time of $10 \%$ peak current.

Table I lists the calculated parameters using a series of $Z$-pinch loads with $R_{\mathrm{RC}}$ of $4 \mathrm{~cm}$ and $l$ of $1.5 \mathrm{~cm}$, while the cavities are charged to $\pm 90 \mathrm{kV}$, an expected voltage for reliable operation. It can be seen that current pulses rising to $\sim 5$ MA in 100 ns can be generated to heavy or large loads, pushing the loads to radial velocities of $10-30 \mathrm{~cm} / \mu \mathrm{s}$. The maximum efficiency from stored energy to radial kinetic energy can be as high as $13 \%$. It also can be seen that the imploding velocities of light yet big loads (nos. 1-3) are $\sim 2$ times to that of the heavy small ones (nos. 4-6).

For comparison, measured parameters of several shots obtained in Sino-Russia joint experiments at Angara-5-1, 2008, are listed in Table II. These shots used tungsten loads 
TABLE I. Calculated parameters for a series of $Z$-pinch loads.

\begin{tabular}{llccccccc}
\hline \hline $\begin{array}{l}\text { Calculation } \\
\text { no. }\end{array}$ & $\begin{array}{c}\text { Mass } \\
(\mathrm{mg} / \mathrm{cm})\end{array}$ & $\begin{array}{c}\text { Initial } \\
\text { radius } \\
(\mathrm{cm})\end{array}$ & $\begin{array}{c}\text { Peak } \\
\text { current } \\
(\mathrm{MA})\end{array}$ & $\begin{array}{c}\text { Rise } \\
\text { time } \\
(\mathrm{ns})\end{array}$ & $\begin{array}{c}\text { Implosion } \\
\text { time } \\
(\mathrm{ns})\end{array}$ & $\begin{array}{c}\text { Velocity } \\
(\mathrm{cm} / \mu \mathrm{s})\end{array}$ & $\begin{array}{c}\text { Kinetic } \\
\text { energy } \\
(\mathrm{kJ})\end{array}$ & $\begin{array}{c}\text { Energy } \\
\text { efficiency } \\
(\%)\end{array}$ \\
\hline 1 & 0.8 & 1.2 & 4.7 & 91 & 136 & 32.5 & 63.2 & 11.6 \\
2 & 1 & 1.2 & 4.9 & 96 & 146 & 29.6 & 65.8 & 12.1 \\
3 & 1.8 & 1.2 & 5.0 & 100 & 178 & 23.5 & 74.3 & 13.7 \\
4 & 3 & 0.6 & 4.6 & 97 & 137 & 16.5 & 60.9 & 11.2 \\
5 & 5 & 0.6 & 4.8 & 102 & 162 & 13.2 & 65.0 & 11.9 \\
6 & 8 & 0.6 & 4.9 & 103 & 191 & 10.9 & 71.5 & 13.1 \\
7 & 0.3406 & 0.6 & 3.3 & 48 & 70 & 34.5 & 32.1 & 5.9 \\
8 & 0.3418 & 0.9 & 3.6 & 50 & 88 & 37.9 & 36.9 & 6.8 \\
\hline \hline
\end{tabular}

with the same parameters as listed in nos. 7 and 8 in Table I. It can be seen that the measured radiated energy is nearly triple the calculated kinetic energy. Similarly, investigations on Saturn find that the radiated energy generated by tungsten arrays with implosion times of 130-200 ns are 2-4 times what could be supplied according to OD calculations [43,44]. That is because the radiated energy, widely used as the figure of merit in experiments, comes not only from the thermalization of the implosion kinetic energy but also from Joule heating and $p d V$ work on the plasma during the stagnation phase [1], which are not characterized by the OD model. Based on that, we could reasonably expect the accelerator to achieve an energy efficiency of $20 \%-30 \%$, which nearly doubles the figure ever obtained in fast $Z$-pinch experiments.

In addition, simple stability scaling arguments assume that the output $\mathrm{x}$-ray pulse width is a multiple of the thermalization time of the radial kinetic energy [45], given by $\Delta r / V_{\max }$, where $\Delta r$ is a characteristic sheath thickness at stagnation and $V_{\max }$ is the maximum imploding velocity. $\Delta r$ depends mainly on RT broadening, which increases with the aspect ratio of initial diameter to dominant RT instability wavelength. Therefore, the load should be designed to generate not only a large $E_{\max }$ but also a high $V_{\max }$, as well as a relatively small initial radius which reduces the interwire separation and improves azimuthal uniformity. Especially, a high $V_{\max }$ after the current peak leads to a fast increase of the load inductance and sharp fall of the driven current; thus, a fraction of the magnetic energy

TABLE II. Measured parameters for tungsten wire arrays in Sino-Russia joint experiments at Angara-5-1, 2008.

\begin{tabular}{lccccc}
\hline \hline $\begin{array}{l}\text { Shot } \\
\text { no. }\end{array}$ & $\begin{array}{c}\text { Mass } \\
(\mu \mathrm{g} / \mathrm{cm})\end{array}$ & $\begin{array}{c}\text { Initial } \\
\text { radius } \\
(\mathrm{cm})\end{array}$ & $\begin{array}{c}\text { Peak } \\
\text { current } \\
(\mathrm{MA})\end{array}$ & $\begin{array}{r}\text { Rise } \\
\text { time } \\
(\mathrm{ns})\end{array}$ & $\begin{array}{c}\text { Radiated } \\
\text { energy } \\
(\mathrm{kJ})\end{array}$ \\
\hline 4650 & 340.6 & 0.6 & 3.6 & 63.9 & 102.9 \\
4651 & 340.6 & 0.6 & 3.5 & 60.8 & 125.0 \\
4653 & 340.6 & 0.6 & 3.1 & 66.0 & 110.9 \\
4649 & 341.8 & 0.9 & 3.2 & 76.6 & 106.0 \\
4652 & 341.8 & 0.9 & 4.4 & 62.8 & 122.5 \\
\hline \hline
\end{tabular}

converts to electric energy and a high voltage is coupled to the load [46], which will aggrandize the Joule heating and enhance $\mathrm{x}$-ray radiation.

\section{CONCLUSIONS}

In summary, the following conclusions can be drawn:

(i) Tests on the 0.8 -MA cavity operated at a repetition rate of $0.1 \mathrm{~Hz}$ demonstrate the excellent reliability and robustness of the LTD technology. The novel trigger utilizing a single input trigger pulse is proved to be a success, which shows great promise for applications on future large current accelerators to reduce the difficulty in trigger systems.

(ii) Based on the architecture of the prototype cavity, we have developed a design for a $Z$-pinch accelerator composed of six modules, each consisting of eight stacked annular LTD cavities in a voltage-adding configuration. All the transmission lines utilized in this design work in vacuum; thus, the high-voltage insulating stack is eliminated. Besides, the accelerator is $3.2 \mathrm{~m}$ tall and $12 \mathrm{~m}$ in outer diameter including supports, which is appreciably compacter than accelerators with similar output but using traditional technology.

(iii) An equivalent circuit model for electromagnetic pulse transmission in MITLs as well as in voltage adders was developed. The 0D thin shell model was employed to characterize the pinch load. Simulation results show that the power flow in the vacuum lines with a minimum $A-K$ gap of $1 \mathrm{~cm}$ behaves well, and the output current can be as high as $\sim 5$ MA with a rise time of $\sim 100 \mathrm{~ns}$. Especially, an implosion velocity of $\sim 30 \mathrm{~cm} / \mu$ s can be generated, leading to an energy efficiency of $11 \%-13 \%$. According to scaling experiment results obtained at Angara-5-1 and Saturn, the efficiency from stored electric energy to radiation can be as high as $20 \%-30 \%$, which nearly doubles the figure ever obtained in fast $Z$-pinch experiments.

(iv) The design of a $5 \mathrm{MA} / 100 \mathrm{~ns} Z$-pinch accelerator on the basis of the LTD in which all the transmission lines are vacuum insulated is theoretically feasible and technically maneuverable in the near future. As no water-vacuum interface exists and all the components work under relative 
low voltage and current, the LTD accelerator possesses the ability of being operated repetitively. It therefore provides a high efficient facility for research on the fast $Z$ pinch.

There are several key research needs to be continued for a full accelerator design. First of all, further study and optimization is imperative to be done on the gas switch, which currently does not fit the requirement of volume application as it prefires frequently. Subsequently, the mechanical support of the LTD modules and the MITLs need to be tested, as well as the serving systems. Furthermore, magnetic nulls exist at the transition region that can be the source of severe current loss, which are not characterized in the equivalent circuit modeling. This effect must be investigated computationally with 3D particle-incell codes and eventually verified experimentally.

\section{ACKNOWLEDGMENTS}

This work was supported by the National Natural Science Foundation of China (Grants No. 11305155 and No. 11475153). The authors are deeply indebted to Dr. Sun Fengju and Dr. Zeng Jiangtao, as well as their team at Northwestern Institute of Nuclear Technology. Their help during the design, assembly, and test of the prototype cavity was invaluable. The entire team was very courteous and eager to educate us on the LTD technology and its operation. We also wish especially to thank Dr. A. A. Kim's team in HCEI for their fruitful work on the conceptual design of the accelerator, as well as the enlightening instructions on inherent issues. The helpful discussions with Jiang Xiaofeng on the multigap gas switch and with Dr. Hu Yixiang on circuit modeling for MITL are greatly appreciated.

[1] D. D. Ryutov, M. S. Derzon, and M. K. Matzen, Rev. Mod. Phys. 72, 167 (2000).

[2] R. B. Spielman et al., Phys. Plasmas 5, 2105 (1998).

[3] T. W. L. Sanford, R. E. Olson, R. L. Bowers, G. A. Chandler, M. S. Derzon, D. E. Hebron, R. J. Leeper, R. C. Mock, T. J. Nash, D. L. Peterson, L. E. Ruggles, W. W. Simpson, K. W. Struve, and R. A. Vesey, Phys. Rev. Lett. 83, 5511 (1999).

[4] D. D. Bloomquist, R. W. Stinnett, D. H. McDaniel, J. R. Lee, A. W. Sharpe, J. A. Halbleib, L. G. Schlitt, P. W. Spence, and P. Corcoran, in Proceedings of the 6th IEEE International Pulsed Power Conference, Arlington, VA, 1987 (IEEE, New York, 1987), p. 310.

[5] W. A. Stygar et al., Phys. Rev. Accel. Beams 12, 120401 (2009).

[6] W. K. Zou, F. Guo, L. Chen, S. Y. Song, M. Wang, W. P. Xie, and J. J. Deng, Phys. Rev. Accel. Beams 17, 110401 (2014).

[7] R. B. Spielman, W. A. Stygar, K. W. Struve, and J. F. Seamen, in Proceedings of the Particle Accelerator Conference, Vancouver, BC, Canada, 1997 (IEEE, New York, 1997).
[8] B. M. Koval'chuk, V. A. Vizir', A. A. Kim, E. V. Kumpyak, S. V. Loginov, A. N. Bastrikov, V. V. Chervyakov, N. V. Tsoi, P. Monjaux, and D. Kh'yui, Russ. Phys. J. 40, 1142 (1997).

[9] A. A. Kim, B. M. Kovalchuk, E. V. Kumpyak, and N. V. Zoi, in Proceedings of the 12th IEEE International Pulsed Power Conference, edited by C. Stallings and H. Kirbie (IEEE, Piscataway, NJ, 1999).

[10] A. A. Kim, B. M. Kovalchuk, A. N. Bastrikov, V. G. Durakov, S. N. Volkov, and V.A. Sinebryukhov, in Proceedings of the 13th IEEE International Pulsed Power Conference (IEEE, New York, 2001).

[11] A. A. Kim, A. N. Bastricov, S. N. Volkov, V. G. Durakov, B. M. Kovalchuk, and V. A. Sinebryuukkov, in Proceedings of the 13th International Symposium on High Current Electronics, http://www.congress-2006.hcei.tsc.ru/cat/ proc_2004/13/Paper_034.pdf.

[12] A. A. Kim, M. G. Mazarakis, V. A. Sinebryukhov, B. M. Kovalchuk, V. A. Vizir, S. N. Volkov, F. Bayol, A. N. Bastrikov, V. G. Durakov, S. V. Frolov, V. M. Alexeenko, D. H. McDaniel, W. E. Fowler, K. LeCheen, C. Olson, W. A. Stygar, K. W. Struve, J. Porter, and R. M. Gilgenbach, Phys. Rev. Accel. Beams 12, 050402 (2009).

[13] A. A. Kim, M. G. Mazarakis, V. I. Manylov, V. A. Vizir, and W. A. Stygar, Phys. Rev. Accel. Beams 13, 070401 (2010).

[14] A. A. Kim, M. G. Mazarakis, V. A. Sinebryukhov, S. N. Volkov, S. S. Kondratiev, V. M. Alexeenko, F. Bayol, G. Demol, and W. A. Stygar, Phys. Rev. Accel. Beams 15, 040401 (2012).

[15] M. G. Mazarakis, R. B. Spielman, K. W. Struve, and F. W. Long, in Proceedings of the 13th IEEE International Pulsed Power Conference (IEEE, New York, 2001).

[16] M. G. Mazarakis, W. E. Fowler, F. W. Long, D. H. McDaniel, C. L. Olson, S. T. Rogowski, R. A. Sharpe, and K.W. Struve, in Proceedings of the 15th IEEE International Pulsed Power Conference (IEEE, New York, 2005).

[17] M. G. Mazarakis, W. E. Fowler, D. H. McDaniel, C. L. Olson, S. T. Rogowski, R. A. Sharpe, K. W. Struve, W. A. Stygar, A. A. Kim, V. A. Sinebryukhov, R. M. Gilgenbach, and M. R. Gomez, in Proceedings of the 16th IEEE International Pulsed Power Conference, Albuquerque, NM (IEEE, Piscataway, NJ, 2007).

[18] M. G. Mazarakis, W. E. Fowler, A. A. Kim, V. A. Sinebryukhov, S. T. Rogowski, R. A. Sharpe, D. H. McDaniel, C. L. Olson, J. L. Porter, K. W. Struve, W. A. Stygar, and J. R. Woodworth, Phys. Rev. Accel. Beams 12, 040501 (2009).

[19] M. G. Mazarakis et al., IEEE Trans. Plasma Sci. 38, 704 (2010).

[20] W. A. Stygar, M. E. Cuneo, D. I. Headley, H. C. Ives, R. J. Leeper, M. G. Mazarakis, C. L. Olson, J. L. Porter, T. C. Wagoner, and J. R. Woodworth, Phys. Rev. Accel. Beams 10, 030401 (2007).

[21] W. A. Stygar, W. E. Fowler, K. R. LeChien, F. W. Long, M. G. Mazarakis, G. R. McKee, J. L. McKenney, J. L. Porter, M. E. Savage, B. S. Stoltzfus, D. M. Van De Valde, and J. R. Woodworth, Phys. Rev. Accel. Beams 12, 030402 (2009).

[22] W. A. Stygar et al., Phys. Rev. Accel. Beams 18, 110401 (2015). 
[23] J. R. Woodworth, J. A. Alexander, F. R. Gruner, W. A. Stygar, M. J. Harden, J. R. Blickem, G. J. Dension, F. E. White, L. M. Lucero, H. D. Anderson, L. F. Bennett, S. F. Glover, D. Van De Valde, and M. G. Mazarakis, Phys. Rev. Accel. Beams 12, 060401 (2009).

[24] J. R. Woodworth, W. E. Fowler, B. S. Stoltzfus, W. A. Stygar, M. E. Sceiford, and M. G. Mazarakis, Phys. Rev. Accel. Beams 14, 040401 (2011).

[25] S. C. Bott, D. M. Haas, R. E. Madden, U. Ueda, Y. Eshaq, G. Collins, IV, K. Gunasekera, D. Mariscal, J. Peebles, and F. N. Beg, Phys. Rev. Accel. Beams 14, 050401 (2011).

[26] B. M. Kovalchuk, A. V. Kharlov, E. V. Kumpyak, and A. A. Zherlitsyn, Phys. Rev. Accel. Beams 16, 050401 (2013).

[27] B. M. Kovalchuk, A. V. Kharlov, E. V. Kumpyak, G. V. Smorudov, and A. A. Zherlitsyn, Rev. Sci. Instrum. 85, 013501 (2014).

[28] T. X. Liang, F. J. Sun, A. C. Qiu, J. T. Zeng, X. D. Liu, X. F. Jiang, Z. G. Liu, and J. H. Yin, in Proceedings of the 17th International Conference on High Power Particle Beams (IEEE, Xi'an, 2008).

[29] T. X. Liang, X. F. Jiang, F. J. Sun, and A. C. Qiu, IEEE Trans. Plasma Sci. 40, 3087 (2012).

[30] P. Liu, F. J. Sun, H. Wei, X. F. Jiang, X. D. Liu, Z. G. Wang, J. H. Yin, T. X. Liang, and A. C. Qiu, IEEE Trans. Plasma Sci. 40, 83 (2012).

[31] W. K. Zou, L. Chen, D. G. Liu, L. Zhang, L. Q. Liu, L. J. Zhou, M. Wang, B. Wei, F. Guo, X. Q. Wang, Y. M. Dai, W. P. Xie, and J. J. Deng, Phys. Rev. Accel. Beams 15, 110401 (2012).

[32] J. H. Yin, P. Liu, H. Wei, F. J. Sun, and A. C. Qiu, IEEE Trans. Plasma Sci. 41, 1837 (2013).
[33] G. Guo, W. K. Zou, L. Q. Liu, L. Chen, B. Wei, D. G. Liu, M. Wang, and W. P. Xie, IEEE Trans. Plasma Sci. 43, 2663 (2015).

[34] M. G. Mazarakis and K. W. Struve, SNL Report No. SAND2006-5811, 2006.

[35] D. L. Smith, M. G. Mazarakis, and C. L. Olson, Fusion Sci. Technol. 52, 922 (2007).

[36] F. J. Sun (private communication).

[37] A. A. Kim (private communication).

[38] W. N. Weseloh, in Proceedings of the 7th Pulsed Power Conference (1989).

[39] C. W. Mendel, D. B. Seidel, and S. E. Rosenthal, Laser Part. Beams 1, 311 (1983).

[40] C. W. Mendel and S. E. Rosenthal, Phys. Plasmas 2, 1332 (1995).

[41] A. A. Samokhin, Plasma Phys. Rep. 36, 149 (2010).

[42] P. F. Ottinger, J. W. Schumer, R. J. Allen, and R. J. Commisso, in Proceedings of the 14th International Pulsed Power Conference (2003).

[43] C. Deeney, C. A. Coverdale, M. R. Douglas, K. W. Struve, R. B. Spielman, W. A. Stygar, D. L. Peterson, and N. F. Roderick, Phys. Plasmas 6, 3576 (1999).

[44] K. G. Whitney, J. W. Thornhill, J. P. Apruzese, J. Davis, C. Deeney, and C. A. Coverdale, Phys. Plasmas 11, 3700 (2004).

[45] D. L. Peterson, R. L. Bowers, J. H. Brownell, A. E. Greene, K. D. McLenithan, T. A. Oliphant, N. F. Roderick, and A. J. Scannapieco, Phys. Plasmas 3, 368 (1996).

[46] C. A. Jennings, M. E. Cuneo, E. M. Waisman, D. B. Sinars, D. J. Ampleford, G. R. Bennett, W. A. Stygar, and J. P. Chittenden, Phys. Plasmas 17, 092703 (2010). 